\title{
Comparison of Oxytocin and Misoprostol in Reduction of Postpartum Hemorrhage
}

\author{
${ }^{1}$ Talaat Dabaghi Ghaleh, ${ }^{1}$ Fatemeh Lalooha, ${ }^{1}$ Faride Movahed, \\ ${ }^{2}$ Simindokht Moradi and ${ }^{3}$ Omid Mashrabi \\ ${ }^{1}$ Department of Obstetrics and Gynecology, ${ }^{2}$ Department of Gynecology, \\ Faculty of Medicine, Ghazvin University of Medical Sciences, Ghazvin, Iran \\ ${ }^{3}$ Women's Reproductive Health Research Center, Department of Obstetrics and Gynecology, \\ Faculty of Medicine, Tabriz University of Medical Sciences, Tabriz, Iran
}

\begin{abstract}
Postpartum hemorrhage ranks among the leading causes of maternal morbidity and mortality, both in developed and developing countries. Intravenous Oxytocin is using now to reduce of postpartum hemorrhage. With this trial, researchers sought to determine the effectiveness of oral Misoprostol as an Uterotonic drug in comparison with intravenous Oxytocin in patients with a low risk of postpartum hemorrhage undergoing delivery. To compare the effect of $400 \mu \mathrm{g}$ of oral Misoprostol with $10 \mathrm{IU}$ of intravenous Oxytocin in preventing postpartum hemorrhage. In a randomized controlled trial conducted in Kosar hospital, 300 pregnant women with inclusion criteria received either $400 \mu \mathrm{g}$ of oral Misoprostol or $10 \mathrm{IU}$ of intravenous Oxytocin after delivery of the anterior shoulder or within $1 \mathrm{~min}$ of delivery. Hemoglobin and hematocrit of maternal was checked during admission and $24 \mathrm{~h}$ after delivery and compared together. There was no difference between two groups in hematocrit drop in $3.33 \pm 3.44$ and $2.81 \pm 1.26 \%$ of the participants in the Oxytocin and Misoprostol group $(\mathrm{p}=0.325)$. The rate of use of additional oxytocin was higher in the Oxytocin group (34.8 vs. $20.5 \%, \mathrm{p}=0.013)$. Shivering was higher in misoprostol group $(12.3$ vs. $2.9 \%, \mathrm{p}=0.005)$. Fever occurred only in 2 cases of Misoprostol group ( $\mathrm{p}=0.236$ ). The routine use of $400 \mu \mathrm{g}$ of oral misoprostol was no less effective than $10 \mathrm{IU}$ of intravenous oxytocin in reducing blood loss after delivery as assessed by change in postpartum hematocrit and hemoglobin.
\end{abstract}

Key words: Postpartum hemorrhage, misoprostol, oxytocin, hemoglobin, uterotonic drug, Iran

\section{INTRODUCTION}

One of the main causes of maternal mortality in the world is hemorrhage. Active administration of the labor process in a way that reduces this risk is one of the important points where the uses of uterotonic drugs play a very important role in preventing postpartum uterine hemorrhage. Intravenous oxytocin drug and oral misoprostol are among the uterotonic.

Oxytocin is used in systems that intravenous injection is accessible. In the country, due to increasing recommendations in support of the physiological labor where the process does not require intravenous access, oral misoprostol can be a proper alternative to oxytocin. Problems such as lack of access to Oxytocin and insufficient blood transfusion service and also the problems in storage and preservation of Oxytocin drugs, worsen postpartum hemorrhage and the anemia acquired during natural process of pregnancy makes this process even more observable. Use of oxytocin during the labor process reduced the risk of postpartum hemorrhage by 40\% (Prendiville et al., 1988). However, these beneficial effects of oxytocin require syringe, needle and trained personnel. It has been shown that prostaglandins are effective in the treatment of postpartum hemorrhage and in such circumstances, they may be more effective than oxytocin, ergometrine or its derivatives (Toppozada et al., 1981; Prendirille et al., 1988). Taking a cheap and effective prostaglandin in the administration of the 3rd phase of labor process to reduce hemorrhage significantly decreases maternal mortality.

In many studies, misoprostol as a PGEI synthetic analogue has been shown as an important factor for this purpose (Hofmeyr et al., 1998; El-Refaey et al., 1997; Bamigboye et al., 1987). And its advantages over other prostaglandins include its stability at high temperatures, low cost and easy accessibility. Meanwhile, it is absorbed rapidly and its quick effect has been shown on the uterus (Karim, 1987; Choo et al., 1998). As part of the prevention of postpartum hemorrhage which reduces the risk of

Corresponding Author: Fatemeh Lalooha, No. 20, Shakeri Alley, Jahad Ave., Imam Street, Ajabshir, East Azarbayjan Province, Iran 
maternal mortality, planning a study of misoprostol in a risky situation seemed wise. Use of Misoprostol as an alternative to oxytocin possesses some benefits including low cost, possibility of oral use and stability at high temperatures.

Widmer et al. (2010) showed that $400 \mu \mathrm{g}$ of oral misoprostol is a proper alternative to 5 units of intravenous oxytocin. Also Kundodyiwa et al. (2001) showed that $400 \mu \mathrm{g}$ of oral misoprostol is comparable to 10 units of intramuscular oxytocin. This study will also test the hypothesis if oral misoprostol can be a proper alternative to oxytocin in decreasing postpartum hemorrhage.

\section{MATERIALS AND METHODS}

This study as a single blind randomized clinical trial was conducted on 300 pregnant women referring to Kosar hospital, 31 of whom were excluded due to lack of necessary qualifications in the study and 269 were included in the complementary study. Pregnant women under study held the following qualifications: singleton cephalic term pregnancies with gestational age $\geq 37$ weeks spontaneous or induced labor and $<3$ for those with estimated birth weight $<4 \mathrm{~kg}$.

Exclusion criteria from the study included instrument of TL operation prior to $24 \mathrm{~h}$ before labor, a history of previa, a history of asthma, coagulopathy and a history of postpartum hemorrhage. At the entering of patient to the maternity ward, a blood sample was taken from her and CBC was done. All the people by the secretary of the ward were randomly divided into two groups with white and blue cards. The first group was given $10 \mathrm{IU}$ of intravenous oxytocin and the second received oral misoprostol $400 \mu \mathrm{g}$ was administered. Administration time of the drugs listed was within the 1st min after labor or fetus' anterior shoulder coming out. The pregnant women under study were then observed and checked for excessive hemorrhage or uterine atony.

When necessary, additional oxytocin was administered and hemorrhage was controlled. About $1 \mathrm{~h}$ after delivery, patients were transferred and upon entering the ward, the patient's vital signs including blood pressure and pulse rate, mother's body temperature and respiration were measured by the ward nurse and the patient's vital signs were also rechecked at the end of the 2nd h after delivery. Subjects were under observation for $24 \mathrm{~h}$ in postpartum ward and their CBC level was rechecked $24 \mathrm{~h}$ after labor. Information on the people under study was collected by a questionnaire designed and attached to the end of this study. This information includes the following:
- Age

- Parity

- Induced labor

- The use of either drugs of oxytocin or misoprostol

- Birth weight

- Need for additional oxytocin to control postpartum hemorrhage

- Maternal hemoglobin and hematocrit levels at admission and $24 \mathrm{~h}$ after delivery

- The mother's body temperature and shivering

Information was entered into questionnaires by residents in the postpartum ward and information related to postpartum including the need for additional oxytocin and hemoglobin and hematocrit $24 \mathrm{~h}$ after delivery were entered by the ward nurse. Shivering and mother's body temperature were also recorded by the ward nurse. The study data was collected through questionnaires and entered into SPSS software and assessed by t-test and Chi-square tests and the power of the test was calculated at the end.

\section{RESULTS}

About 269 out of 300 pregnant women participating in the study were qualified to be included in the study. About 137 people were in the group receiving oxytocin and 132 were in the group receiving misoprostol. Mean age of people under study was 24.27 years in Oxytocin group and 24.19 years in the Misoprostol group Std. was 5.56 for the 1 st group and 5.33 for the $2 \mathrm{nd}(\mathrm{p}=0.9)$. And therefore, there is no significant difference between the two groups in terms of age.

Out of Oxytocin group, 51 patients $(37.7 \%)$ had zero parity, 58 patients (42\%) parity of 1 and $28(2.3 \%)$ had parity of 2. Out of Misoprostol group, 55 people (41.7\%) had zero parity, $50(37.9 \%)$ parity of 1 and $27(20.4 \%)$ parity of 2 that there was no significant differences between the two groups in terms of distribution of parity $(\mathrm{p}=0.151)$.

About 30 people $(24.8 \%)$ out of Oxytocin group and 45 patients $(36.6 \%)$ out of Misoprostol group were induced that no significant differences was observed between the two groups $(\mathrm{p}=0.053)$. About $96(76.8 \%)$ of the Oxytocin group and $95(74.2 \%)$ of the Misoprostol group had episiotomy that there was no significant difference between the two groups $(\mathrm{p}=0.633)$. In terms of 1,2 and 3 grade ruptures, there were 18 patients $(81.8 \%)$ in the Oxytocin group and 12 patients $(66.7 \%)$ in the Misoprostol group that there was no significant 
Res. J. Biol. Sci., 6 (12): 652-655, 2011

Table 1: Hemoglobolin and hematocrit drop between two groups

\begin{tabular}{llcc}
\hline Parameters & Drug & Mean \pm SD & p-values \\
\hline Hemoglobolin drop & Oxytocin & $1.23 \pm 0.98$ & 0.820 \\
& Misoprostol & $1.27 \pm 1.26$ & \\
Hematocrit drop & Oxytocin & $3.33 \pm 3.44$ & 0.325 \\
& Misoprostol & $2.81 \pm 4.37$ & \\
\hline
\end{tabular}

difference between the two groups $(\mathrm{p}=0.300)$. The drop in hematocrit level was calculated as $3.33 \pm 3.44 \%$ in the Oxytocin group and $2.81 \pm 4.31 \%$ in the Misoprostol group that $\mathrm{t}$-test analysis showed no significant differences between the two groups $(\mathrm{p}=0.325)$ (Table 1). The drop in hemoglobin levels was calculated as $1.23 \pm 0.96$ $\mathrm{mg} \mathrm{dL}^{-1}$ in the Oxytocin group and $1.27 \pm 1.26 \mathrm{mg} \mathrm{dL}^{-1}$ in the Misoprostol group that t-test analysis showed no significant differences in these measures $(\mathrm{p}=0.820)$ (Table 1). Among the Oxytocin group, 47 patients (34.8\%) received additional Oxytocin during labor due to postpartum hemorrhage but in the Misoprostol group, 26 patients $(20.5 \%)$ required additional oxytocin during labor $(\mathrm{p}=0.013)$. About 6 patients $(4.4 \%)$ in the postpartum section and $5(3.9 \%)$ in the Misoprostol group required additional oxytocin $(\mathrm{p}=1.000)$.

In the Oxytocin group, none of the mothers had temperature, $\geq 38^{\circ} \mathrm{C}$ but in the Misoprostol group, 2 patients had temperature, $>38^{\circ} \mathrm{C}$. And there was no significant difference between the two groups $(\mathrm{p}=0.236)$. About 4 patients $(2.9 \%)$ in the Oxytocin group and 16 patients $(12.3 \%)$ in the Misoprostol group had postpartum shivering. Hence, shivering was observed in the Misoprostol group $(\mathrm{p}=0.005)$. Also at the end of the test, the power of the test was calculated as 0.4 .

\section{DISCUSSION}

According the conducted study, there was no difference between the two groups in terms of drop in hematocrit levels. About $3.33 \pm 3.44 \%$ in the Oxytocin group and $2.81 \pm 4.31 \%$ in the Misoprostol group $(\mathrm{p}=0.325)$. Consequently, this study shows that misoprostol has effects similar to oxytocin on reducing postpartum hemorrhage and can be a good alternative to reduce the rate of hemorrhage. In a study Widmer et al. (2010) concluded that $400 \mu \mathrm{g}$ of oral misoprostol is comparable to 5 IU of intravenous oxytocin and can be a proper alternative. Similar results were also obtained by the study conducted at the Kosar Hospital Center of Qazvin city that $400 \mu \mathrm{g}$ of oral misoprostol can be the alternative to intravenous Oxytocin 10 IU.

In the study by Kundodyiwa et al. (2001) in Harare Hospital, Zimbabwe, the intramuscular of Misoprostol and oral Misoprostol in administration of the 3rd phase of labor were compared that no difference was observed in hematocrit level drop in both groups which is similar to the results of the study in Kosar hospital. In the study, the incidence of shivering was higher in the Misoprostol group, similar to the results obtained from Kundodyiwa et al. (2001) study in which shivering was higher in the Misoprostol group. In the study in Kosar hospital, the incidence of fever was not significantly different in the two groups but results by Widmer et al. (2010) study showed that the incidence of fever was higher in the Misoprostol group but the increased fever was not clinically significant but self-limited.

Also in the study by Kundodyiwa et al. (2001), fever rate was observed higher in the Misoprostol group. In the study by Widmer et al. (2010), Misoprostol group required additional Oxytocin to control hemorrhage and eventually, the hemorrhage was controlled taking the prescribed additional oxytocin. In the study of Kosar center, application of additional oxytocin was much more required in the Oxytocin group which may be due to the shorter half-life of oxytocin compared to Misoprostol. Therefore, additional oxytocin is required to control hemorrhage in cases in which oxytocin is used to reduce postpartum hemorrhage.

\section{CONCLUSION}

Also in the study by Kundodyiwa et al. (2001), there was no significant difference at the next use of oxytocin in the two groups. According to the results by the study of Kosar center, benefits of $400 \mu \mathrm{g}$ oral Misoprostol is comparable to $10 \mathrm{IU}$ of oxytocin and regarding the increasing recommendations for the physiological labor process where the patients do not require intravenous access during admission, oxytocin can be replaced with oral misoprostol which is cheap and easily accessible, and its effect is significantly immediate and regarding the existing problems in the blood transfusion service, it plays a significant role in the prevention of obstetric hemorrhage. Since, a large sample size is required to demonstrate the minor differences in tests, further studies are recommended to be conducted in the future to emphasize the results of this study.

\section{ACKNOWLEDGEMENTS}

The special thanks and appreciations go to the staff of Obstetrics and Postpartum wards of Kosar Hospital, and all colleagues who cooperated in this project.

\section{REFERENCES}

Bamigboye, A.A., G.J. Hofmeyr and D.A. Merrell, 1987. Rectal misoprostol in the prevention of postpartum hemorrhage: A placebo-controlled trial. Am. J. Obstet. Gynecol., 179: 1043-1046. 
Choo, W.L., S. Chua, Y.S. Chong, K. Vanaja and P.L. Oei et al., 1998. Correlation of change in uterine activity to blood loss in the third stage of labour. Gynecol. Obstet. Invest., 46: 178-180.

El-Refaey, H., P. O'Brien, W. Morafa, J. Walder and C. Rodeck, 1997. Use of oral misoprostol in the prevention of postpartum haemorrhage. Br. J. Obstet. Gynaecol., 104: 336-339.

Hofmeyr, G.J., V.C. Nikodem, M. de Jager and B.R. Gelbart, 1998. A randomised placebo controlled trial of oral misoprostol in the third stage of labour. Br. J. Obstet. Gynaecol., 105: 971-975.

Karim, A., 1987. Antiulcer prostaglandin misoprostol: Single and multiple dose pharmacokinetic profile. Prostaglandins, 33: 40-50.
Kundodyiwa, T.W., F. Majoko and S. Rusakaniko, 2001. Misoprostol versus oxytocin in the third stage of labor. Int. J. Gynaecol. Obstet., 75: 235-241.

Prendiville, W., D. Elbourne and I. Chalmers, 1988. The effects of routine oxytocic administration in the management of the third stage of labour: An overview of the evidence from controlled trials. Br. J. Obstet. Gynaecol., 95: 3-16.

Toppozada, M., M. El-Bossaty, H.A. El-Rahman and A.H. El-Din, 1981. Control of intractable atonic postpartum hemorrhage by 15 -methyl prostaglandin F2 alpha. Obstet. Gynecol., 58: 327-330.

Widmer, M., J. Blum, G.J. Hofmeyr, G. Carroli and H. Abdel-Aleem et al., 2010. Misoprostol as an adjunct to standard uterotonics for treatment of postpartum haemorrhage: A multicentre, double-blind randomised trial. Lancet, 375: 1808-1813. 